\title{
Controlling the plasma electron number density of copper metal using NIR picosecond laser-induced plasma spectroscopy
}

\author{
Mohamed FIKRY ${ }^{1,2}$, WALID TAWFIK ${ }^{3 *}$, MAgDY OMAR ${ }^{1}$ \\ ${ }^{1}$ Department of Physics, Faculty of Science, Cairo University, Cairo, Egypt \\ ${ }^{2}$ Egypt Nanotechnology Center (EGNC), Cairo University, Cairo, Egypt \\ ${ }^{3}$ National Institute of Laser Enhanced Sciences (NILES), Cairo University, Cairo, Egypt \\ *Corresponding author: walid_tawfik@niles.edu.eg
}

\begin{abstract}
In this paper, we investigate a new method to control the plasma electron number density of copper metal using a near-infrared (NIR) picosecond Nd:YAG laser-induced plasma spectroscopy (LIPS) technique. The applied laser parameters are as follows; laser pulse energy and intensity varied from 29.2 to $59.4 \mathrm{~mJ} \pm 3 \%$ and from $6.01 \times 10^{10}$ to $12.35 \times 10^{10} \mathrm{~W} / \mathrm{cm}^{2} \pm 5 \%$, respectively, for a single pulse at 170 ps pulse duration, and beam diameter about $0.5 \pm 0.1 \mathrm{~mm}$. By considering the Stark broadening of a specific spectral line, electron density can be calculated using a neutral copper line at $521.8 \mathrm{~nm}$, assuming the local thermodynamic equilibrium (LTE) condition. The observed electron density values were $1.09 \times 10^{16}, 2.24 \times 10^{16}, 3.60 \times 10^{16}$, and $4.75 \times 10^{16} \mathrm{~cm}^{-3}$ for the laser pulse energies $29.2,41,52.4$, and $59.4 \mathrm{~mJ}$, respectively. The plasma electron density values are increased with the increase in laser pulse energy. Such findings were interpreted due to an increase in the mass ablation rates with laser pulse energy. The obtained results explore the ability to control the plasma electron density by controlling the picosecond pulse energy. These results can contribute to the development of plasma technologies and their applications in many fields.
\end{abstract}

Keywords: picosecond, LIPS, copper, electron density, Stark broadening.

\section{Introduction}

The plasma produced a hot gas composed of a mixture of neutral atoms, electrons, and ions by an exaggerated change in a substance temperature to vanquish the binding electrostatic forces between electrons and nucleus [1]. The plasma radiation was affected by the properties of both the target and its surroundings [2] . Laser-induced plasma spectroscopy is an essential diagnostic method in plasma treating and technology. The finest suitable orderings for plasmas are distinguished into two main groups according to their temperature. The first group, the high temperature or fusion plasma 
where, its plasma temperature $T_{\mathrm{e}}$ values ranged $10^{6}-10^{8} \mathrm{~K}$ while, the second, the low temperature or gas discharge where $T_{\mathrm{e}}$ values ranged from $10^{3}$ to $10^{4} \mathrm{~K}[\underline{3}]$.

The laser-induced plasma spectroscopy (LIPS) [4] is one of the most fundamental and essential plasma production techniques, by focusing a high fluence laser pulse on the target material. The generated radiation can cause fast, local heating, intense evaporation, and degradation of the material at the focal point [ $\underline{5}]$.

The interaction between the laser beam and the material depends on the physical and chemical properties of the target. Besides, the properties of the laser such as the laser wavelength, fluence, intensity, and pulse width, affect such interaction as well [6].

The LIPS technique is suitable for the essential evaluation of the material phases and is used to estimate the ratio of the target's impurities components with a creative calibration-free method []].

In the recent decade, picosecond laser has been an important topic of research applications [ ] . Picosecond laser applications include optical coherence tomography, new solutions for optical communications, and laser ultra-short pulse management. The processing of picosecond laser materials delivers many vital advantages over conventional procedures: a rapid, accurate, and versatile technique, due to the electron-phonon interaction and faster vaporization of the target substance than energy transferred throughout the surrounding areas [9]. Also, previously it has been shown that picosecond pulses induce plasma material processing with reduced heat-affected zone and less heat dissipation compared to nanosecond pulsed laser processing [10].

The previous literature survey indicated that LIPS is related to laser pulse parameters. In 2000, KomPITSAS et al. [11] used the LIPS technique to analyze environmental samples using nanosecond pulsed Nd:YAG laser at IR $(1.06 \mu \mathrm{m})$ and UV $(355 \mathrm{~nm})$ with varied pulse energy from 10 to $50 \mathrm{~mJ}$. They concluded that the quality of the spectra depends on the various experimental parameters. In 2002, ABDELLATIF and IMAM studied the plasma laser parameters achieved by the nanosecond Nd:YAG laser at varying laser wavelengths $(1064,532$, and $355 \mathrm{~nm})$ with different laser pulse energies $(60,100$, and $500 \mathrm{~mJ}$ ) for aluminum plates at different focusing lengths [12]. They determined that the maximum value of the $T_{\mathrm{e}}$ was found at a certain distance away from the target surface depending on the laser wavelength, whereas the electron density $N_{\mathrm{e}}$ reaches its highest value near the target surface. In 2010, UNNIKRISHNAN et al. studied time-resolved $\mathrm{Nd}$ :YAG laser operated at $355 \mathrm{~nm}$, a pulse width of $6 \mathrm{~ns}$, a repetition rate of $10 \mathrm{~Hz}$, and laser pulse irradiance of $4.5 \times 10^{8} \mathrm{~W} / \mathrm{cm}^{2}$ to induce $\mathrm{Cu}$ plasma spectroscopy of neutral atom and ion line emissions at atmospheric pressure [13]. They indicated that the optimum delay time is considered from the temporal evolution of the intensity ratio of two $\mathrm{Cu}$ I lines, assuming plasma optically thin and local thermodynamic equilibrium (LTE) conditions necessary for the LIPS analysis of samples. In 2013, NAEEM et al. measured the pure copper plasma parameters applying a $532 \mathrm{~nm} \mathrm{Nd:YAG} \mathrm{pulsed} \mathrm{laser} \mathrm{with} \mathrm{pulse}$ duration of $5 \mathrm{~ns}$ and $10 \mathrm{~Hz}$ repetition rate at pulse energies of 17.6 and $88.6 \mathrm{~mJ}$ [14]. They concluded that there was a direct relationship between the plasma parameters and the laser irradiation, whereas they were inverse to the distance from the sample surface. In 2015, Messaoud Aberkane et al. determined the effect of $50 \mathrm{~mJ} \mathrm{Nd:YAG} \mathrm{laser}$ 
wavelengths 1064,532 , and $355 \mathrm{~nm}$ at 7, 9, and $10 \mathrm{~ns}$ pulse duration in the air at atmospheric pressure on the correlation between $T_{\mathrm{e}}$ and surface hardness of Fe-V-C metallic alloys [15]. They decided that the surface hardness measurement using LIPS is more efficient by the IR wavelength than the UV for the excitation laser. In 2019, the ultrafast femtosecond laser with pulse wavelength $800 \mathrm{~nm}$, pulse duration of $50 \mathrm{fs}$ and $1.9 \mathrm{~mJ}$ laser energy, was used by Xu et al. to generate a high $T_{\mathrm{e}}$ and low $N_{\mathrm{e}}$ plasma with strong spectral intensity by changing the space between the focusing lens and the sample surface in the LIPS configuration [16]. They found that the plasma condition at high $T_{\mathrm{e}}$ and low $N_{\mathrm{e}}$ can be used to improve the spectral resolution of LIPS.

In this work, we aim to generate a plasma breakdown and diagnosis of the plasma profile of a copper target by using laser-induced plasma spectroscopy via the picosecond laser. The emission lines of LIPS spectra are studied in the visible region. The combined effects of NIR laser wavelength at different laser pulse energies on the plasma plume electron density were measured. We intentionally try to control a specific region of plasma density by controlling the picosecond laser plus energy.

\section{Methodology}

In this experiment, the plasma was produced using the ultrafast picosecond $Q$-switched Nd:YAG laser (SL334, Eksapla, Lithuania) at NIR wavelength $1064 \mathrm{~nm}$ single-shot pulse.

The laser-generated different laser pulse energies $E_{\mathrm{p}}: 29.2,41,52.4$ and $59.4 \mathrm{~mJ}$ $\pm 3 \%$, which produced different laser pulse fluencies $F_{\mathrm{p}}$ and intensities $I_{\mathrm{p}}$ range from 10 to $21 \mathrm{~J} / \mathrm{cm}^{2} \pm 3 \%$ and $6.01 \times 10^{10}$ to $12.35 \times 10^{10} \mathrm{~W} / \mathrm{cm}^{2} \pm 5 \%$, respectively, for pulse duration 170 ps. A laser power meter (model 11 Maestro, Standa Ltd., Lithuania) was used to monitor the energy of each laser pulse with an accuracy in the range $\pm 1 \%$. The schematic diagram of the used LIPS setup is shown in Fig. 1. A plano-convex quartz lens with $150 \mathrm{~mm}$ focal length was used to focus the laser beam on the $\mathrm{Cu}$ disk target with a spot size of about $0.5 \pm 0.1 \mathrm{~mm}$ to produce a plasma plume, where the diameter of the spot was adjusted by changing the distance between the laser lens and the target. The copper target was placed on the $x y z$ micro-scanning stage. The plasma

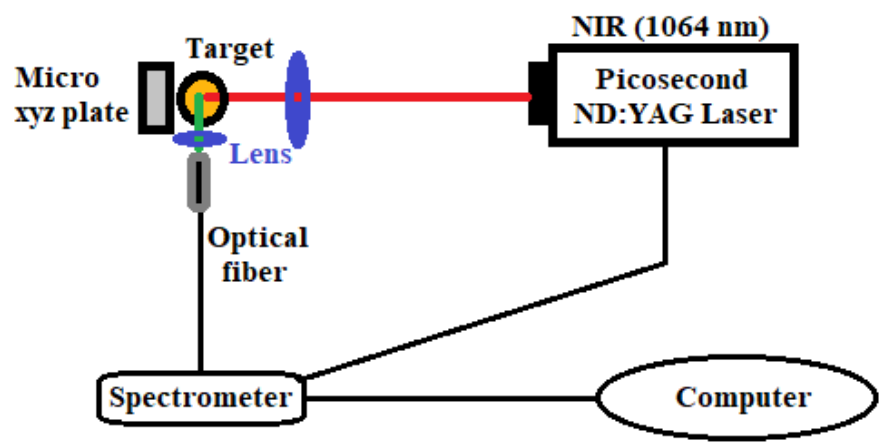

Fig. 1. A schematic diagram of LIPS system. 
emission lines were collected by a plano-convex quartz lens with $100 \mathrm{~mm}$ focal length, which was positioned at an angle of approximately $90^{\circ}$ to the laser beam axis, to focus the collected light on an optical fiber ( $400 \mu \mathrm{m}$ core diameter) to be delivered to an Ocean Optics spectrometer model (HR4000 UV-NIR) covering an optical range from 200 to $1100 \mathrm{~nm}$. The delay and integration times were adapted to 1 and $10 \mu \mathrm{s}$, respectively, which were considered as optimum conditions to obtain the LTE plasma hypothesis as found before [17].

\section{Result and discussion}

\subsection{LIPS spectrum studies}

A qualitative compositional analysis of the $\mathrm{Cu}$ target was observed using the optical emission spectrum of the laser-produced plasma created by a single-shot picosecond $\mathrm{Nd}$ :YAG laser. The Nd:YAG laser generates pulses at $1064 \mathrm{~nm}$, with tuned intensity values gradually from about $6.01 \times 10^{10}$ to $12.35 \times 10^{10} \mathrm{~W} / \mathrm{cm}^{2} \pm 5 \%$, respectively.

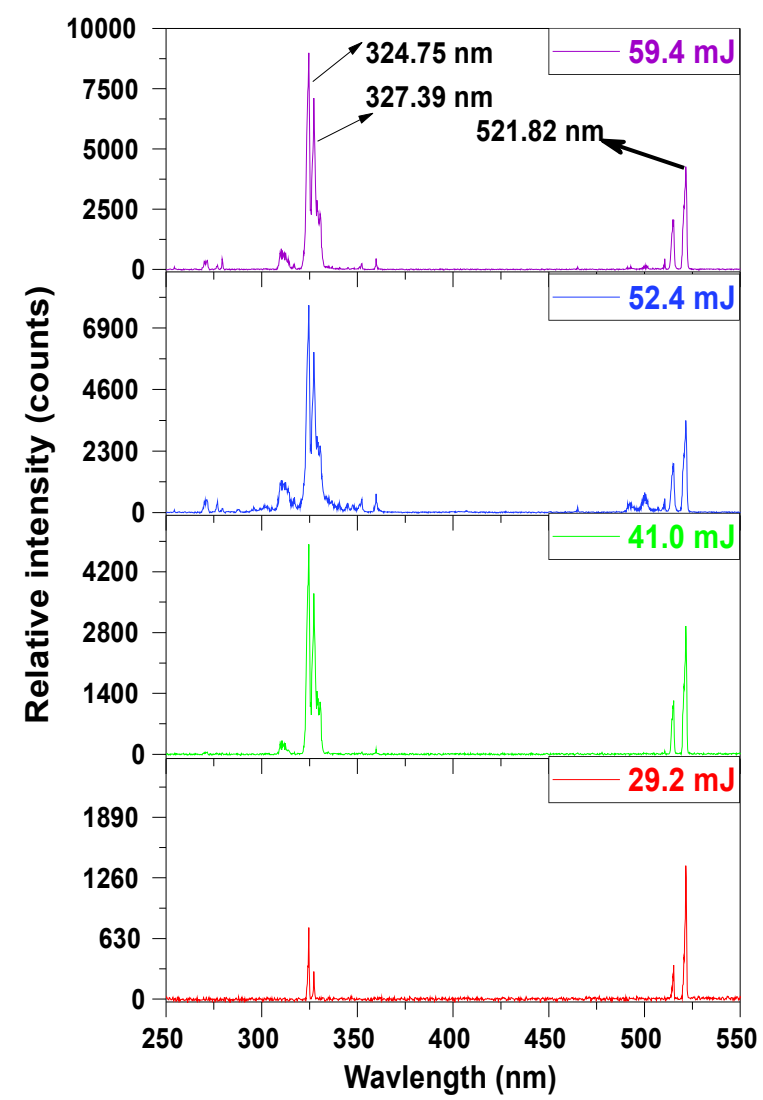

Fig. 2. LIPS emission spectra of $\mathrm{Cu}$ target using laser pulse energies from around 29.2 to $59.4 \mathrm{~mJ}$ using NIR laser wavelength. 
$\mathrm{T}$ a b 1 e. Spectroscopic parameters of the emission line of $\mathrm{Cu}$ I used to calculate the plasma electron density, taken from the NIST database [18].

\begin{tabular}{|c|c|c|c|c|c|}
\hline \multirow{2}{*}{$\begin{array}{l}\text { Wavelength } \\
{[\mathrm{nm}]}\end{array}$} & Transitions & \multirow{2}{*}{$\begin{array}{l}\text { Transition probability } \\
A_{k i}\left[10^{7} \mathrm{~s}^{-1}\right]\end{array}$} & \multicolumn{2}{|c|}{ Energies $[\mathrm{eV}]$} & \multirow[b]{2}{*}{$-g_{k}$} \\
\hline & $\overline{\text { Upper level }}$ & & $\overline{E_{k}}$ & $E_{i}$ & \\
\hline 324.75 & $3 d^{10} 4 p, 2 P_{3 / 2} \rightarrow 3 d^{10} 4 s,{ }^{2} S_{1 / 2}$ & 13.95 & 3.816 & 0.000 & 3.816 \\
\hline 327.39 & $3 d^{10} 4 p, 2 P_{1 / 2} \rightarrow 3 d^{10} 4 s,{ }^{2} S_{1 / 2}$ & 13.70 & 3.785 & 0.000 & 3.785 \\
\hline 521.82 & $3 d^{10} 4 d, 2 D_{5 / 2} \rightarrow 3 d^{10} 4 p,{ }^{2} P_{3 / 2}$ & 7.500 & 6.192 & 3.816 & 6.000 \\
\hline
\end{tabular}

The LIPS emission spectra of the $\mathrm{Cu}$ sample covering the wavelength range from 250 to $550 \mathrm{~nm}$ at different laser pulse energies 29.2, 41, 52.4, and $59.4 \mathrm{~mJ}$ using $1064 \mathrm{~nm}$ laser wavelength are shown in Fig. 2. This spectral region is selected because it gathers the highest $\mathrm{Cu}$ emission lines intensities, under optically thin and plasma in LTE as crucial conditions for the measurements of plasma parameters. The selected characteristic line of singly ionized copper is Cu I $521.82 \mathrm{~nm}$ due to the transitions $3 d^{10} 4 d$, $2 D_{5 / 2} \rightarrow 3 d^{10} 4 p,{ }^{2} P_{3 / 2}$.

The characteristics and transitions of the selected $\mathrm{Cu}$ emission line have been identified with the help of the NIST database as shown in the Table, where these data were used to calculate the plasma electron density [18].

\subsection{Plasma electron density}

In order to estimate the plasma electron density, we have considered the Stark broadening profile of $\mathrm{Cu}$ I $521.8 \mathrm{~nm}$. The fundamental linewidth $\Delta \lambda_{\text {FWHM }}$ is determined by deconvolution for each observed line profile as a Voigt profile using Origin software version 9.5 at a fixed laser NIR wavelength and different laser pulse energies as represented in Fig. 3. Assuming LTE conditions, as well be verified later, the electron density is considered by adopting Boltzmann distribution of the electron density as follows $[19,20]$ :

$$
N_{\mathrm{e}} \approx \frac{\Delta \lambda_{\mathrm{FWHM}}}{2 W_{\mathrm{e}}} \times 10^{16}
$$

where $N_{\mathrm{e}}$ is the electron density (in $\mathrm{cm}^{-3}$ ), $\Delta \lambda_{\mathrm{FWHM}}$ is the fundamental line width at half maximum and $W_{\mathrm{e}}$ is the electron impact parameter (Stark broadening value). The average value of the $W_{\mathrm{e}}$ for $\mathrm{Cu}$ I $521.8 \mathrm{~nm}$ is $0.180 \mathrm{~nm}$, as given by previous work Popov et al. [21]. The Stark line width $\Delta \lambda_{\mathrm{FWHM}}$ can be corrected by subtracting the instrumental $\left(\Delta \lambda_{\text {instrument }}\right)$ from the observed line width $\left(\Delta \lambda_{\text {observed }}\right)$ as follows [22] :

$$
\Delta \lambda_{\text {FWHM }}=\Delta \lambda_{\text {observed }}-\Delta \lambda_{\text {instrument }}
$$

The observed values of the plasma electron density at different laser pulse energy values of 29.2, 41, 52.4, and $59.4 \mathrm{~mJ}$ are shown in Fig. 4. It can be implied that the plasma electron density values considered for the $\mathrm{Cu}$ emission lines are increased from 


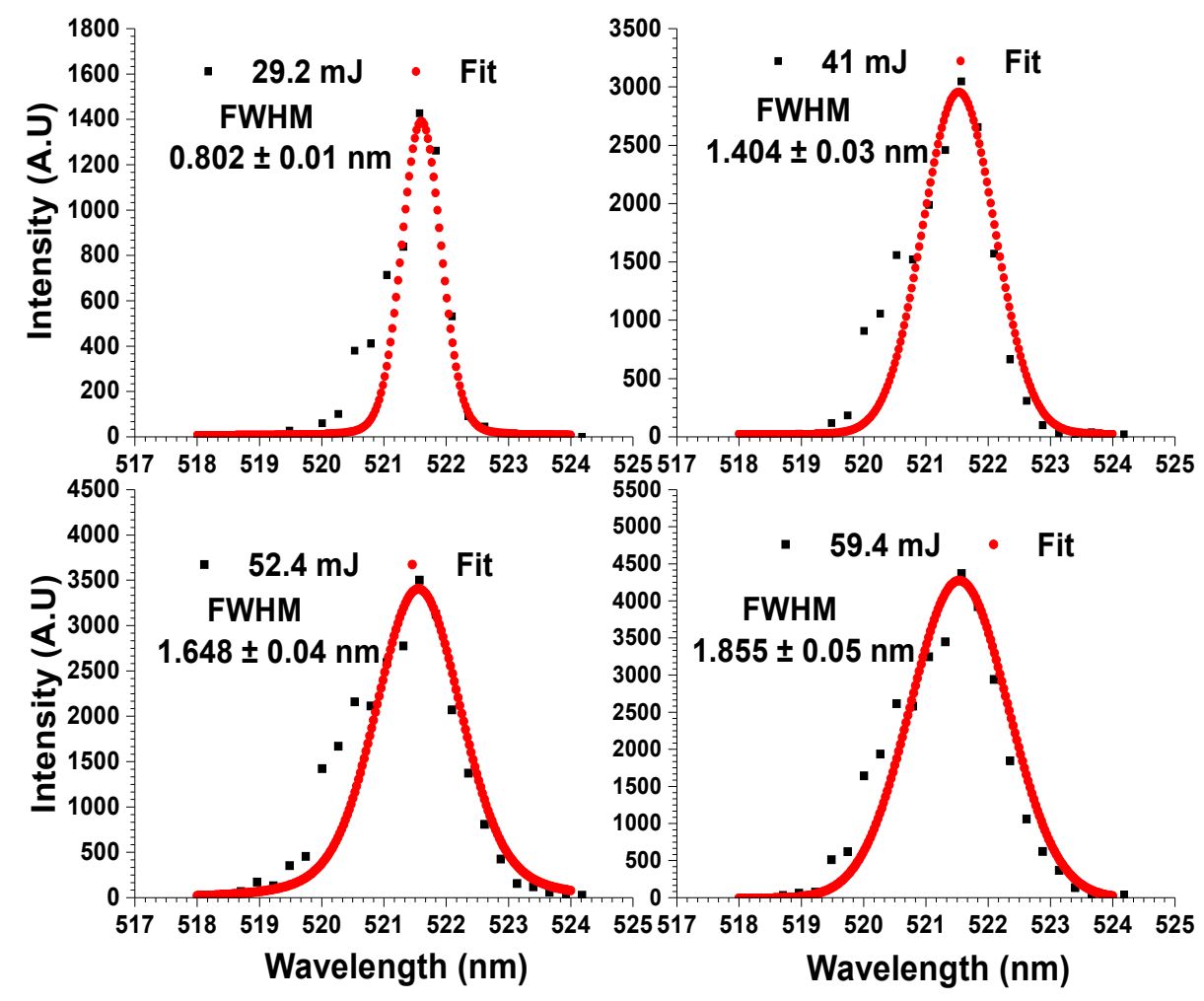

Fig. 3. Line profile of $\mathrm{Cu}$ I lines at $521.8 \mathrm{~nm}$ fitted with Voigt function using Origin software version 9.5 for $29.2,41,52.4$, and $59.4 \mathrm{~mJ}$ pulse energy using NIR laser wavelength.

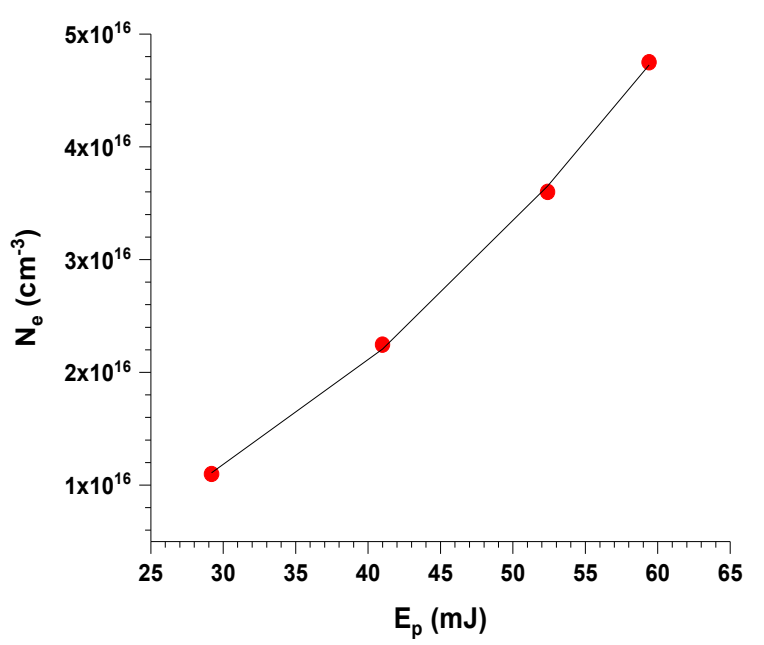

Fig. 4. The dependence of the plasma electron density $N_{\mathrm{e}}$ on the laser pulse energy $E_{\mathrm{p}}$ for 29.2, 41.0, 52.4, and $59.4 \mathrm{~mJ}$ pulse energy for $\mathrm{Cu} \mathrm{I}$ line $521.8 \mathrm{~nm}$ using NIR laser wavelength. 
about $1.09 \times 10^{16}$ to $4.75 \times 10^{16} \mathrm{~cm}^{-3}$ depending on the laser pulse energy, which is in agreement with previous results by others $[\underline{23}-\underline{25}]$.

This increase of the electron density with the laser pulse energy can be understood due to an increase in the mass-ablation rate $\left(\mathrm{m}^{\bullet}\right)$ with the increase of the laser pulse energy [26, 27] as indicated in Eq. (3). Equation (3) is a semi-empirical model developed by RaCiUKAITIS et al. [228], in addition to QI and LAI [29] as follows:

$$
m^{\bullet}=\rho V^{\bullet}=\rho \frac{\pi w^{2} d_{0}}{4}\left(\ln \frac{2 E_{\mathrm{p}}}{\pi w^{2} F_{\text {p.c }}}\right)^{2}
$$

where $V^{\bullet}$ is the ablation volume rate per a single shot pulse, $\rho$ is the solid target density, $w$ is the beam waist of the laser beam at the target surface, $d_{0}$ is the effective absorption depth of the target, $E_{\mathrm{p}}$ is the laser pulse energy, $F_{\mathrm{p} . \mathrm{c}}$ is the critical threshold fluence of the laser. Equation (3) represents the evidence that the mass ablation rate is increasing with the laser pulse energy. The latter retain more energetic electrons, i.e., higher electron density with the increase of the picosecond laser pulse energy $[\underline{30}, \underline{31}]$.

To verify the LTE condition, the critical electron density, proposed by the criterion given by McWhirter, is considered as follows [․ $\underline{20}]$ :

$$
N_{\mathrm{e}} \geq 1.6 \times 10^{12} \times \Delta E^{3} \times T_{\mathrm{e}}^{(1 / 2)}
$$

where $\Delta E$ is the highest energy difference between the upper and the lower energy level $(\mathrm{eV})$ and $T_{\mathrm{e}}$ is the plasma temperature $(\mathrm{K})$.

The plasma temperature is measured from the emission lines intensities of $\mathrm{Cu}$ by applying the Boltzmann plot method $[\underline{5}, \underline{32}]$, which is given by

$$
\ln \frac{I \lambda}{A_{k i} g_{k}}=-\frac{1}{K T_{\mathrm{e}}} E_{k}+\ln \frac{F C}{U(T)}
$$

where $I$ is the intensity of the spectral line, $\lambda$ is the wavelength of the spectral line, $K$ is the Boltzmann constant, $A_{k i}$ is the transition probability, $g_{k}$ is the statistical weight for the upper level, $E_{k}$ is the exciting level energy, $T_{\mathrm{e}}$ is the plasma temperature, $C$ is the species concentration, $F$ is an experimental factor and $U(T)$ is the partition function.

Figure 5 demonstrates Boltzmann plots for $\mathrm{Cu} \mathrm{I}$ lines $(324.75,327.39$, and $521.82 \mathrm{~nm}$ ) where the $\ln \left(I \lambda / A_{k i} g_{k}\right)$ is considered for every exciting energy level $E_{k}$ applying the highest laser pulse energy of $59.4 \mathrm{~mJ}$. The associated electron temperature can be considered from the slope into Eq. (5) which is found to be $13492 \mathrm{~K}$ with an uncertainty of about $\pm 8 \%$.

The $\mathrm{Cu}$ emission spectral line $324.73 \mathrm{~nm}$ is the highest energy difference $(\Delta E=$ $=3.816 \mathrm{eV}$ ) line, as given in the Table. According to the right-hand side of Eq. (4), the $N_{\mathrm{e}}$ is considered for $\mathrm{Cu} I 324.73 \mathrm{~nm}$, where $\Delta E$ is $3.816 \mathrm{eV}$, and the $T_{\mathrm{e}}$ is $13492 \mathrm{~K}$ which gives $N_{\mathrm{e}}$ value of $1.03 \times 10^{16} \mathrm{~cm}^{-3}$. On the other hand, the observed electron density value of the $\mathrm{Cu}$ lines for the minimum laser pulse energy $(29.2 \mathrm{~mJ})$ is 


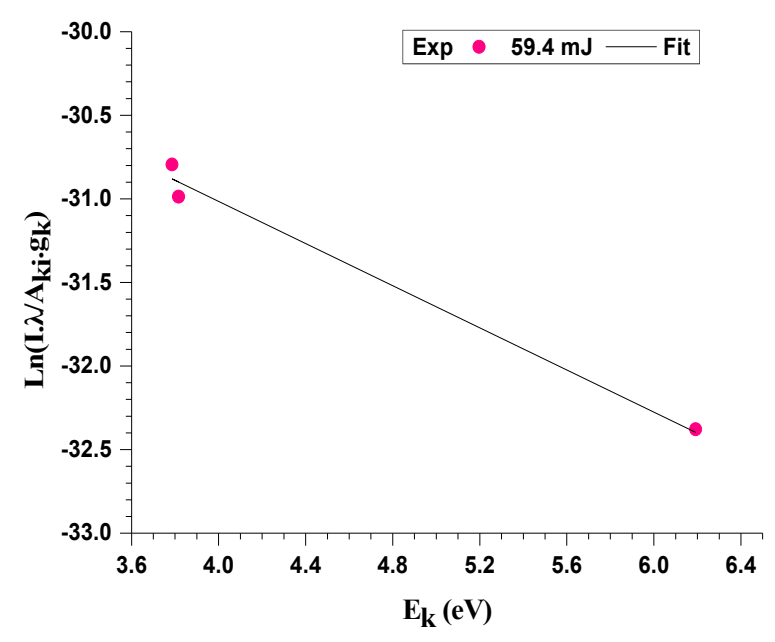

Fig. 5. Boltzmann plots for the $\mathrm{Cu}$ I lines $(324.75,327.39$, and $521.82 \mathrm{~nm})$ using NIR laser wavelength.

$1.1 \times 10^{16} \mathrm{~cm}^{-3}$ as shown in Fig. 4. So, according to McWhirter by validation relation (4), the studied plasma can be considered in the assumption of LTE and optically thin conditions $[\underline{7}, \underline{20}]$.

\section{Conclusion}

This work presented a new method to control the plasma electron number density of copper metal using the NIR picosecond LIPS method with varied pulse energy. It has been observed that the copper emission spectra intensities and electron density have shown strong dependence on the laser pulse energy, due to increasing the mass ablation rate with the laser energy. So, most of the laser energy would be absorbed by the free electrons of the target, especially at higher laser fluence, and preserve more energetic electrons, i.e., it increases the electron density. These effects can explain the observed increase of plasma electron density values of $\mathrm{Cu}$ I line $521.8 \mathrm{~nm}$ with increasing the laser pulse energy gradually from around 29.2 up to $59.4 \mathrm{~mJ}$. These obtained results can be applied to control the plasma densities in many technological applications.

\section{References}

[1] Adhikari B.R., Khanal R., Introduction to the plasma state of matter, Himalayan Physics 4(4), 2013, pp. 60-64, DOI: 10.3126/hj.v4i0.9430.

[2] CoOper J., Plasma spectroscopy, Reports on Progress in Physics 29, 1966, pp. 35-130, DOI: 10.1088/ 0034-4885/29/1/302.

[3] Fantz U., Basics of plasma spectroscopy, Plasma Sources Science and Technology 15(4), 2006, pp. S137-S147, DOI: 10.1088/0963-0252/15/4/S01.

[4] Rusak D.A., CAstle B.C., Smith B.W., Winefordner J.D., Fundamentals and applications of laser -induced breakdown spectroscopy, Critical Reviews in Analytical Chemistry 27(4), 1997, pp. 257-290, DOI: $10.1080 / 10408349708050587$. 
[5] Ahmad K., Tawfik W., Farooq W.A., Singh J.P., Analysis of alumina-based titanium carbide composites by laser-induced breakdown spectroscopy, Applied Physics A 117, 2014, pp. 1315-1322, DOI: $10.1007 / \mathrm{s} 00339-014-8544-7$.

[6] Thiem T.L., Salter R.H., Gardner J.A., Lee Y.I., Sneddon J., Quantitative simultaneous elemental determinations in alloys using laser-induced breakdown spectroscopy (LIBS) in an ultra-high vacuum, Applied Spectroscopy 48(1), 1994, pp. 58-64, DOI: 10.1366/0003702944027615.

[7] Moнamed W.T.Y., Calibration free laser-induced breakdown spectroscopy (LIBS) identification of seawater salinity, Optica Applicata 37(1-2), 2007, pp. 5-19.

[8] Jarota A., Pastorczak E., Tawfik W., Xue B., Kania R., Abramczyk H., Kobayashi T., Exploring the ultrafast dynamics of a diarylethene derivative using sub-10 fs laser pulses, Physical Chemistry Chemical Physics 21(1), 2019, pp. 192-204, DOI: 10.1039/c8cp05882b.

[9] SugioKa K., Progress in ultrafast laser processing and future prospects, Nanophotonics 6(2), 2017, pp. 393-413, DOI: 10.1515/nanoph-2016-0004.

[10] Ding P., Hu B., Li Y., Numerical simulation of copper ablation by ultrashort laser pulses, http:// arxiv.org/abs/1107.3710 (accessed June 2020).

[11] Kompitsas M., Roubani-Kalantzopoulou F., Bassiotis I., Diamantopoulou A., Giannoudakos A., Laser induced plasma spectroscopy (LIPS) as an efficient method for elemental analysis of environmental samples, EARSeL eProceedings, No. 1, 2000, pp. 130-138.

[12] Abdellatif G., Imam H., A study of the laser plasma parameters at different laser wavelengths, Spectrochimica Acta Part B: Atomic Spectroscopy 57(7), 2002, pp. 1155-1165, DOI: 10.1016/ S0584-8547(02)00057-5.

[13] Unnikrishnan V.K., Alti K., Kartha V.B., Santhosh C., Gupta G.P., Suri B.M., Measurements of plasma temperature and electron density in laser-induced copper plasma by time-resolved spectroscopy of neutral atom and ion emissions, Pramana - Journal of Physics 74(6), 2010, pp. 983-993, DOI: $10.1007 / \mathrm{s} 12043-010-0089-5$.

[14] Naeem M.A., IQbal M., Amin N., MusadiQ M., Jamil Y., Cecil F., Measurement of electron density and temperature of laser-induced copper plasma, Asian Journal of Chemistry 25(4), 2013, pp. 2192 -2198, DOI: 10.14233/ajchem.2013.13392.

[15] Messaoud Aberkane S., Bendib A., Yahiadui K., Abdelli-Messaci S., Amara S.E., Harith M.A., Effect of laser wavelength on the correlation between plasma temperature and surface hardness of $\mathrm{Fe}-\mathrm{V}-\mathrm{C}$ metallic alloys, Spectrochimica Acta Part B: Atomic Spectroscopy 113, 2015, pp. 147-151, DOI: $\underline{10.1016 / \mathrm{j} . \mathrm{sab} .2015 .09 .012 .}$.

[16] Xu W., Chen A., Wang Q., Zhang D., Wang Y., Li S., Jiang Y., Jin M., Generation of high-temperature and low-density plasma with strong spectral intensity by changing the distance between the focusing lens and target surface in femtosecond laser-induced breakdown spectroscopy, Journal of Analytical Atomic Spectrometry 34(5), 2019, pp. 1018-1025, DOI: 10.1039/c8ja00359a.

[17] Aslam Faroog W., TawfiK W., Al-Mutairi F.N., Alahmed Z.A., Qualitative analysis and plasma characteristics of soil from a desert area using LIBS technique, Journal of the Optical Society of Korea 17(6), 2013, pp. 548-558, DOI: 10.3807/JOSK.2013.17.6.548.

[18] Kramida A., Ralchenko Y., Reader J., NIST ASD Team (2018), NIST Atomic Spectra Database (ver. 5.6.1), http://physics.nist.gov/asd (accessed August 11, 2014), National Institute of Standards and Technology, Gaithersburg, MD, DOI: 10.18434/T4W30F.

[19] Mohamed W.T.Y., Improved LIBS limit of detection of Be, $\mathrm{Mg}, \mathrm{Si}, \mathrm{Mn}$, Fe and Cu in aluminum alloy samples using a portable Echelle spectrometer with ICCD camera, Optics and Laser Technology 40(1), 2008, pp. 30-38, DOI: 10.1016/j.optlastec.2007.04.004.

[20] Mortazavi S.Z., Parvin P., Mousavi Pour M.R., Reyhani A., Moosakhani A., Moradkhani S., Time-resolved evolution of metal plasma induced by $Q$-switched Nd:YAG and ArF-excimer lasers, Optics and Laser Technology 62, 2014, pp. 32-39, DOI: 10.1016/j.optlastec.2014.02.006.

[21] Popov A.M., Sushrov N.I., Zaytsev S.M., Labutin T.A., The effect of hyperfine splitting on Stark broadening for three blue-green $\mathrm{Cu}$ I lines in laser-induced plasma, Monthly Notices of the Royal Astronomical Society 488(4), 2019, pp. 5594-5603, DOI: 10.1093/mnras/stz1874. 
[22] QINDEEL R., TAWFIK W., Measurement of plasma characteristics of the optically generated copper plasma by laser spectroscopy technique, Optoelectronics and Advanced Materials - Rapid Communications 8(7-8), 2014, pp. 741-746.

[23] CABAlin L.M., LASERNa J.J., Experimental determination of laser induced breakdown thresholds of metals under nanosecond Q-switched laser operation, Spectrochimica Acta Part B: Atomic Spectroscopy 53(5), 1998, pp. 723-730, DOI: 10.1016/S0584-8547(98)00107-4.

[24] BOGAERTS A., CHEN Z., Effect of laser parameters on laser ablation and laser-induced plasma formation: a numerical modeling investigation, Spectrochimica Acta Part B: Atomic Spectroscopy 60(9-10), 2005, pp. 1280-1307, DOI: 10.1016/j.sab.2005.06.009.

[25] TAN S., Wu J., Zhang Y., Wang M., Ou Y., A model of ultra-short pulsed laser ablation of metal with considering plasma shielding and non-Fourier effect, Energies 11(11), 2018, article 3163, DOI: $\underline{10.3390 / \text { en } 11113163 .}$.

[26] Hussain T., Gondal M.A., Shamraiz M., Determination of plasma temperature and electron density of iron in iron slag samples using laser induced breakdown spectroscopy, IOP Conference Series: Materials Science and Engineering 146, 2016, article 012017, DOI: 10.1088/1757-899X/146/1/012017.

[27] Murbat H.H., Hamza H.A., The influence of Nd: YAG laser energy on plasma characteristics produced on Si: Al alloy target in atmosphere pressure, Journal of Materials Sciences and Application 1(1), 2017, pp. 1-7, DOI: $10.17303 / \mathrm{jmsa} .2017 .1 .101$.

[28] Raciukaitis G., Brikas M., Gedvilas M., Efficiency aspects in processing of metals with high-repetition-rate ultra-short-pulse lasers, ICALEO, M403, 2008, pp. 176-184, DOI: 10.2351/1.5061377.

[29] QI H., LAI H., Micromachining of metals and thermal barrier coatings using a $532 \mathrm{~nm}$ nanosecond fiber laser, Physics Procedia 39, 2012, pp. 603-612, DOI: 10.1016/j.phpro.2012.10.079.

[30] HAMAD A.H., Effects of different laser pulse regimes (nanosecond, picosecond and femtosecond) on the ablation of materials for production of nanoparticles in liquid solution, [In] High Energy Short Pulse Lasers, [Ed.] R. Viskup, IntechOpen, 2016, DOI: 10.5772/63892.

[31] Hoffman J., Moscicki T., Szymanski Z., The effect of laser wavelength on heating of ablated carbon plume, Applied Physics A 104, 2011, pp. 815-819, DOI: 10.1007/s00339-011-6420-2.

[32] Liu H.C., Mao X.L., Yoo J.H., Russo R.E., Early phase laser induced plasma diagnostics and mass removal during single-pulse laser ablation of silicon, Spectrochimica Acta Part B: Atomic Spectroscopy 54(11), 1999, pp. 1607-1624, DOI: 10.1016/S0584-8547(99)00092-0.

Received June 8, 2020

in revised form July 27, 2020 